\title{
INICIAÇÃO SEXUAL FEMININA: TRAJETÓRIA E PRÁTICAS LIGADAS A RELACIONAMENTOS AFETIVOS
}

\author{
Adriele Cristine de Freitas Batista, Raul Aragão Martins. \\ Universidade Estadual Paulista Júlio Mesquita Filho - UNESP, Curso de Pedagogia, São José do Rio Preto, SP. Email: \\ adrielecfb@hotmail.com
}

\begin{abstract}
RESUMO
Falar sobre sexo ainda revela-se uma temática geradora de desconforto entre os envolvidos, mais ainda quando criados numa cultura que insiste em subestimar mulheres e, para além disso, manter sobre elas um determinado controle, principalmente sobre sua trajetória sexual. Diante desse quadro o objetivo deste trabalho foi verificar a trajetória de relações sexuais de universitárias e conferir se sua prática esteve estreitamente relacionada a algum tipo de relacionamento afetivo. Foram participantes do trabalho cinco alunas de uma universidade pública, campus situado em uma cidade do interior do estado de São Paulo, que em dois momentos responderam a uma entrevista semiestruturada numa sala reservada. Os dados coletados a partir da entrevista puderam comprovar que às mulheres são reforçados determinados papéis sociais como a necessidade de relacionamentos amorosos e o cultivo por parte das universitárias de um ideal de primeira relação, na qual preferem iniciar sua vida sexual estando num relacionamento duradouro uma vez que compreendem ter construído afinidade, confiança e intimidade com seu parceiro.
\end{abstract}

Palavras-chave: Iniciação sexual. Trajetória. Práticas. Universitárias.

\section{SEXUAL FEMALE INITIATION: TRAJECTORY AND PRACTICES RELATED TO AFFECTIVE RELATIONSHIPS}

\begin{abstract}
Talking about sex still proves to be a source of discomfort among those involved, especially when raised in a culture that insists on underestimating women and, moreover, maintaining a certain control over them, especially their sexual trajectory. Given this framework, the objective of this study was to verify the trajectory of sexual relations of university students and to verify if their practice was closely related to some type of affective relationship. Five students from a public university, a campus located in a city in the interior of the state of São Paulo, participated in the study, which in two moments answered a semi-structured interview in a reserved room. The data collected from the interview showed that women are reinforced certain social roles such as the need for relationships and the cultivation of university students in an ideal of first relation, in which they prefer to start their sexual life in a lasting relationship once they understand built affinity, trust and intimacy with your partner.
\end{abstract}

Keywords: Sexual initiation. Trajectory. Practices. College students. 


\section{INTRODUÇÃO}

O presente estudo nasce do desejo em entender as motivações ao longo do processo histórico sobre a organização social marcadamente diferenciada entre os gêneros e o modo como elas refletem nas práticas sexuais femininas. Ressalvo a importância em apresentar que este trabalho é fruto de um projeto maior desenvolvido em formato de Trabalho de Conclusão de Curso (TCC) para obtenção do título em Licenciatura em Pedagogia. Deste modo, e em função das particularidades deste trabalho, serão apresentadas brevemente as discussões levantas durante o desenvolvimento da pesquisa maior as motivações e trajetórias sexuais vivenciadas por mulheres ao longo da história.

Antes de mais nada falar em processos históricos significa reconhecer nos sujeitos a capacidade de criar e recriar valores e regras sociais. É entender que cada movimentação dos sujeitos ou de elementos externos a eles é parte de um processo cíclico, na qual novas formas de organização e modos de relação social são exigidas. Por conseguinte, é compreender os sujeitos enquanto seres sociais ativos e produtores de novas culturas.

Esta pesquisa propõe uma breve exposição de que as crenças sobre a sexualidade feminina não são características apenas da sociedade pós-moderna; seus traços, cobranças e prescrições estão presentes desde a Pré-História. De acordo com Auad (2003) no chamado período Paleolítico, ou Idade da Pedra, período vigorosamente representado por lutas pela sobrevivência, os povos da época consideravam a natureza como provedora da humanidade, e com ela tinham uma relação direta de modo que reforçavam o prestígio pela mãe-terra. O corpo da mulher era considerado um receptáculo mágico (abrigo acolhedor escolhido por uma instância maior, no caso a natureza) uma vez que os povos admitiam a vida pré-natal das crianças proveniente da terra, água, natureza ou grutas e do sopro da mãe-terra no ventre da mãe-humana. Desconhecia-se, portanto, o vínculo entre sexo e procriação e por isso acreditavam que os homens não contribuíam na fertilidade, sendo ela uma característica exclusivamente feminina.

Além de produzir gente o corpo da mulher era enaltecido pelo fato de prover alimento e por deter o poder de fazer com que o órgão sexual masculino erguesse e sentisse prazer sexual. Ainda que a mulher fosse aparentemente superior ao homem nesse período às relações interpessoais não eram marcadamente divididas em esferas públicas e privadas, não tendo a ideia exclusiva entre parceiros (monogamia) (AUAD, 2003).

Lins (2012), ao comentar sobre o período Neolítico, nos informa uma nova configuração de organização dos povos e o reconhecimento do homem de sua contribuição no processo de reprodução que permite a instalação do patriarcado. A herança antes cultural passa a ser material e genética adquirindo à mulher a condição de mercadoria e assumindo um importante papel na multiplicação dos bens da sociedade. O controle da sexualidade feminina, o surgimento do casamento, o enaltecimento da virgindade e a monogamia feminina como valores e regras, e a dependência econômica e psicológica das mulheres também são consequências da instalação do patriarcado.

Nas civilizações gregas, período da Antiguidade Clássica, a mulher era considerada menor e, por isso, dependente da tutela de um homem - seja ele pai, irmão, marido ou filho. A demais a mulher exercia papel secundário na sociedade e era destinada ao casamento sem que houvesse seu próprio consentimento (LINS, 2012).

Lins (2012), em O Livro do Amor, também aponta que o casamento nada mais era do que negócios financeiros entre famílias elitistas, caracterizando sua realização sem a necessidade de sentimentos amorosos. Servia ao homem como um meio de assegurar a legitimidade do seu descendente, que lhe cuidaria e administraria seus bens, e de ascender socialmente tornando-se orador ou general. Provedora de dotes ao marido à mulher ficava a responsabilidade de transmitir valores e princípios da família e do patrimônio. 
A civilização romana também teve grande importância no período da Antiguidade Clássica, uma vez que influenciou definitivamente o mundo ocidental como conhecemos hoje. Dessa vez com um elemento a mais a ideia de procriação e perpetuação da família se mantinha: a perpetuação do nome da família do marido e uma criação militar para os filhos homens, reconhecidos pelo pai, que mais tarde seriam soldados de Roma. O reconhecimento do filho ou da filha pelo pai era extremamente importante, não bastava à mulher dar a luz ao recém-nascido, como destaca Auad (2003). Como se pode observar as relações interpessoais eram fortemente influenciadas por um combinado social favorável aos interesses econômicos e a preservação da virilidade masculina.

Há ainda que se considerar um importante fato histórico gerador de uma nova moral em Roma: o Cristianismo. Com este movimento os cidadãos romanos passaram a ignorar os próprios desejos, luxos e prazeres, em função da fé que lhes prometia a eternidade.

Esse marco na civilização romana adota comportamentos hostis em relação ao aborto e ao abandono de crianças, o que até então era visto como uma normalidade. Além das mulheres, Lins (2012) também aponta outros grupos sociais que eram inferiorizados socialmente, as quais viúvas que dormiam com seus protetores eram condenadas como homossexuais e adúlteros, esses sendo homens ou mulheres. Estes dois últimos grupos sofriam repressões em função de suas condutas sexuais, pois nessa época era exaltada a moderação, visto que a prática sexual deveria servir apenas para a procriação. Neste contexto coube a mulher o papel de companheira e a naturalização da sua inferioridade.

Como vimos mudanças não são imediatas, mas graduais. As gerações herdam características sociais e culturais e delas rompem alguns elementos na busca por novos combinados, novas configurações, que caracterizarão um novo período. Nessa perspectiva a Antiguidade Tardia supõe a continuidade e a ruptura de alguns modos de vivência do fim da Antiguidade Clássica entre e os modos de vivência do início da Idade Média.

No período da Idade Média, conhecida como Idade das Trevas, as civilizações deram continuidade em alguns resultados conquistados e aprimoraram outros do período da Antiguidade Clássica. O acesso à cultura reforçava a existência de classes sociais, as manifestações sociais tornaram-se alvos de repressões, e ao ganhar destaque à religião progride no seu domínio sobre os modos de relacionamento dos povos.

Auad (2003) e Lins (2012) apontam o sentimento amoroso entre um homem e uma mulher um elemento que deveria ser de cuidado, de amizade. Cônjuges só eram autorizados a dormir nus se fosse a serviço da procriação, e aos homens e mulheres solteiras qualquer prática que não tivesse a mesma finalidade era considerada infame. É nesse momento que práticas como a masturbação, a homossexualidade e a prostituição são alvos de repúdio à moralidade cristã.

Passado alguns anos surge, com o avanço econômico, uma renovação ideológica e social. Este renascimento no século XII muda a percepção sobre as mulheres, que agora passam a ser pouco mais respeitadas. Estas ganham oportunidades profissionais, passam a serem contribuintes no rendimento da família e ganham voz nas decisões familiares, ou seja, são significativas na participação social e econômica. Sobretudo vale ressaltar que é apenas um pequeno início na mudança de percepção sobre as mulheres, sabe-se que até os dias de hoje as mulheres são menos valorizadas e ocupantes de espaços desprivilegiados. Além disso, homens e mulheres, ainda que vivenciem uma renovação ideológica e social, se veem presos a uma moralidade cristã.

Durante o processo histórico também houve mudanças estruturais da civilização. As cidades europeias, que agora criam e produzem, se expandiram a partir da forte contribuição do comércio e da indústria. Homens e mulheres ocupam espaços no mercado de trabalho, entretanto, a valorização não acontece de igual para igual (LINS, 2012). Como vemos socialmente, aos homens ficam disponíveis cargos de chefia, os quais exigem raciocínio lógico, conhecimento de logística e de mundo, e administração. Às mulheres são oferecidos cargos secundários, de 
subserviência, os quais exigem "dotes naturais", isto é, a manutenção de um ambiente harmônico, acolhedor, organizado e limpo.

Além disso, temos a valorização diferenciada entre homens e mulheres não apenas na distribuição e execução dos serviços, mas prioritária e vigorosamente, nos modos de comportamento de cada um. Às mulheres cobram-se comportamentos relacionados à "boa imagem", à "boa moça", nada mais do que representar os bons costumes da moralidade cristã em que se valoriza a castidade, a docilidade, a bondade. Ao contrário dos homens, estes precisam comprovar socialmente sua imponência e virilidade. Em suma, a eles é permitido o gozo pela vida e diversão enquanto às mulheres a incessante busca por padrões éticos e morais da sociedade.

\section{MÉTODO}

Esta é uma pesquisa de cunho qualitativo, descritiva, a qual propõe coletar, analisar e avaliar o fenômeno social iniciação sexual feminina. Resultante da pesquisa "PERCEPÇÃO DOS DIREITOS SEXUAIS ENTRE UNIVERSITÁRIAS E O PAPEL SOCIAL DESEMPENHADO DENTRO E FORA DO AMBIENTE FAMILIAR" este trabalho foi analisado pelo Comitê de Ética em Pesquisa do Instituto de Biociências, Letras e Ciências Exatas da Universidade Estadual Paulista, que recebeu o Número do Parecer: 1.733.322 e CAAE: 57016016.9.0000.5466.

Para seu desenvolvimento foi utilizado o método de entrevista em profundidade semiestruturada, inspirada em Seidman (1997), que propõe a coleta de dados a partir de entrevistas realizadas em três momentos distintos, sendo esta pesquisa adaptada para uma coleta de dados em apenas dois momentos. Foram participantes dessa pesquisa cinco alunas regularmente matriculadas nos cursos de graduação, todas declaradas ativas sexualmente. Anterior ao início da coleta de dados foi entregue as estudantes o Termo de Consentimento Livre e Esclarecido (TCLE) a fim de comprovar o único interesse acadêmico sobre os dados e o sigilo das participantes. A coleta de dados foi realizada numa sala reservada com o auxílio de um gravador de voz entre os meses de junho e julho de 2017. Os dados coletados foram transcritos em documento de Word, analisados e agrupados em cinco categorias: tipo de relacionamento; fonte de informações; conversas; papel do parceiro e sensações/prazer.

\section{RESULTADOS}

Os dados coletados proporcionaram a análise da trajetória sexual das participantes, o que facilita entender as influências e expectativas sobre sua conduta. A idade média da primeira relação sexual entre as participantes foi aproximadamente 17 anos.

Dentre as participantes três estavam em um relacionamento estável (namoro) na época em que iniciaram sua atividade sexual e duas estavam solteiras. É importante considerar que uma, entre as duas participantes que declaram estar solteira, expôs sua condição de "estar há um tempo com seu parceiro", pressupondo o relacionamento do tipo "ficar". Esse dado torna-se relevante na medida em que é um dos fatores que influencia sua decisão em iniciar sua atividade sexual. De acordo com os estudos de Heilborn et al (2006) a iniciação sexual feminina, diferentemente da masculina, que a considera como uma atividade "técnica" e sem a obrigação de respeito para com as mulheres, é compreendida como um momento que pressupõe a construção afetiva com o parceiro. Em outras palavras, a temporalidade do relacionamento é um fator extremamente importante na medida em que representa o laço e a intimidade estabelecida com seu parceiro. Desse modo, a mulher é capaz de provar sua feminilidade e reforçar o seu valor. Podemos perceber a categoria "tipo de relacionamento" predominantemente caracterizada por uma relação afetiva na fala de quatro das cinco participantes, que são exemplificados nos relatos a seguir apresentados. As partes entre parênteses são acréscimos da pesquisadora para um melhor entendimento do texto e ou para identificação da participante: 
[...] já fazia quase um ano que a gente tava junto, então não foi só começar a namorar e já fazer, mas eu esperei bastante tempo pra ver se a gente ia continuar junto mesmo. $(\mathrm{H}, 20$ anos).

Os relatos evidenciam que a motivação "tipo de relacionamento" para o início da atividade sexual das participantes não era suficiente. As participantes também afirmam a necessidade de conhecer previamente o que seria experienciado, originando a categoria "fonte de informação". Majoritariamente enfatizaram as amigas como fonte principal para obtenção de informação e troca de experiências, seguida da família, internet e ginecologista. Camargo e Botelho (2007), em pesquisa sobre sexualidade com adolescentes, confirmam a informação acima ao constatarem que os amigos são os principais interlocutores quando o assunto é sexualidade, isto se deve ao fato de que os amigos são capazes de promover maior abertura sem que haja um juízo negativo sobre as experiências compartilhadas (SAVEGNAGO; ARPINI, 2013).

Ao passo que as entrevistas foram acontecendo as participantes se sentiram a vontade para relatar com detalhes as primeiras conversas que tiveram com suas amigas e famílias após iniciarem sua relação sexual. Na categoria "conversas" os dados são apresentados em duas partes. Na primeira, a escolha da pessoa para quem a participante contou sobre sua primeira relação está intrinsicamente relacionada às questões de confiança e afinidade. Na segunda, escolher não contar a princípio para a família revela que ao longo dos anos um dos principais influenciadores para essa dificuldade de abertura pode estar relacionada a uma educação conservadora. Pesquisas como de Almeida e Centa (2009) não apenas traduz, mas compreende a dificuldade que as famílias sentem em conversar com seus filhos questões mais delicadas como a sexualidade.

No que tange ao "papel do parceiro", duas dentre as cinco entrevistadas, apontam que sofreram violência psicológica como meio de convencimento para dar início a sua vida sexual. Oliveira (2014), ao estudar o namoro na adolescência, aponta a predominância da violência psicológica nos diferentes tipos de relacionamento. Para a autora é possível identificar a violência psicológica a partir dos seguintes tipos:

a) verbal/emocional, com itens tais como mencionar algo de ruim que o parceiro fez no passado, dizer coisas para deixá-lo com raiva, falar com ele em tom de voz hostil, insultar, ridicularizar na frente dos outros (10 itens); b) relacional: tentar virar os amigos contra o parceiro, dizer coisas sobre ele aos seus amigos, para virá-los contra ele, espalhar boatos sobre ele ( 3 itens); c) ameaças: destruir ou ameaçar destruir algo de valor do parceiro, tentar amedrontá-lo, ameaçar machucá-lo, ameaçar bater nele ou jogar coisa sobre ele (4 itens). (p. 709)

A partir das entrevistas podemos notar a presença da violência psicológica do tipo verbal/emocional. Nesse caso, o tipo de violência é existente na medida em que o parceiro tem como principal objetivo deixar a namorada exclusivamente refém do seu afeto e proteção.

Ele começou na minha cabeça "se não vou largar de você, que não sei o que", essas coisas, sabe? E eu com aquilo na cabeça, não queria largar dele, gostava muito dele e fui [...] (G, 21 anos).

\section{DISCUSSÃO}

Diante da pesquisa desenvolvida temos que ainda há uma prescrição determinada aos comportamentos femininos para que possam ser consideradas mulheres "de valor" e consequentemente implicar num possível relacionamento estável. Tudo isso em função da cultura machista que cultiva a classificação delas em "para uma noite" e "para casar".

Além disso, a análise dos dados permitiu identificar que não se tem mais a expectativa que a iniciação sexual da jovem aconteça dentro de um relacionamento estável considerada namoro. Os relatos apontam que o critério fundamental para iniciar sua vida sexual é o fator tempo de relação, não necessariamente a nomenclatura desta. Isto é, em consonância com as prescrições de 
séculos passados, ainda há uma expectativa sobre a duração do relacionamento com o parceiro, uma vez que, aparentemente, representa uma construção de afinidade, confiança e intimidade.

O estudo também traz a discussão sobre o diálogo com a família a respeito da virgindade da participante. Apesar de acontecer com menor grau de rigidez, quando este acontece, o diálogo é realizado pela mãe e com determinados cuidados como, por exemplo, a manutenção do sigilo perante a sociedade.

\section{CONCLUSÃO}

A partir do contexto apresentado podemos reafirmar a precisão de uma educação sexual que considere a sexualidade em toda a sua amplitude. Isto significa que discutir a relação sexual, bem como o órgão reprodutor é tão importante quanto discutir o modo como me relaciono com o outro, a maneira como me reconheço, me expresso e me identifico. Dentro dessa perspectiva não há uma classificação de prioridades em uma temática ser mais importante que a outra, trata de entendê-las como complementares.

Desse modo, creditamos à escola uma fonte propulsora para aprendizagem e conhecimento, principalmente no que tange às discussões a respeito da sexualidade. Ela, além de oferecer a instrução formal a partir da sistematização dos conhecimentos, é a instituição capaz de acionar nossas melhores potências. Assim, há o compromisso de desconstruir as assimetrias que inferiorizam as mulheres e sua atuação no mundo.

É importante que todos tenham acesso ao discurso que não subestima a capacidade e o valor da mulher, além de não associar suas atividades ao caráter biológico reprodutor. Portanto, concluímos a constante necessidade de discussão sobre a temática de modo a romper com as construções sociais e entender que a mulher também tenha conhecimento do próprio corpo e o exercício pleno da sua sexualidade.

\section{REFERÊNCIAS}

AUAD, Daniela. Feminismo: que história é essa?. 1. ed. Rio de Janeiro: DP\&A, 2003. v. 1. 106p.

ALMEIDA, Ana Carla Campos Hidalgo de; CENTA, Maria de Lourdes. A família e a educação sexual dos filhos: implicações para a enfermagem. Acta paul. enferm., São Paulo , v. 22, n. 1, p. 7176, Feb. 2009.

CAMARGO, Brigido V; BOTELHO, Lúcio J. Aids, sexualidade e atitudes de adolescentes sobre proteção contra o HIV. Rev. Saúde Pública, São Paulo, v. 41, n. 1, p. 61-68, Feb. 2007. https://doi.org/10.1590/S0034-89102006005000013

HEILBORN, Maria Luiza; BOZON, Michel. Iniciação à sexualidade: modos de socialização, interações de gênero e trajetórias individuais. In: Maria Luiza Heilborn; Estela Aquino; Daniela Knauth; Michel Bozon. (Org.). O aprendizado da sexualidade: reprodução e trajetórias sociais de jovens brasileiros.1ed.Rio de Janeiro: Garamond, 2006, vol. 1, p. 155-210.

LINS, Regina Navarro. O livro do amor., volume 1. Rio de Janeiro: BestSeller, 2012.

SAVEGNAGO, Sabrina Dal Ongaro; ARPINI, Dorian Mônica. Conversando sobre sexualidade na família: olhares de meninas de grupos populares. Cad. Pesqui., São Paulo , v. 43, n. 150, p. 924947, Dec. 2013.

SEIDMAN, Irving E. Interview as qualitative research: a guide for researchers in education and the social sciences, 2 ed. Columbia University - New York and London, 1997. 
OLIVEIRA, Queiti Batista Moreira et al . Namoro na adolescência no Brasil: circularidade da violência psicológica nos diferentes contextos relacionais. Ciênc. saúde coletiva, Rio de Janeiro, v. 19, n. 3, p. 707-718, Mar. 2014. 